UDK: 621.38:620.9

DOI: https://doi.org/10.24867/05BE00Stajic

\title{
OBNOVLJIVI IZVORI ENERGIJE U ZAŠTIĆENIM PODRUČJIMA I POTENCIJAL KORIŠĆENJA SOLARNE ENERGIJE U MANASTIRU KOVILJ
}

\section{RENEWABLE ENERGY SOURCES IN NATURE RESERVES AND THE POTENTIAL OF SOLAR ENERGY USE IN KOVILJ MONASTERY}

\author{
Dragana Stajić, Vladimir Katić, Fakultet tehničkih nauka, Novi Sad
}

\section{Oblast - ELEKTROTEHNIKA I RAČUNARSTVO}

Kratak sadržaj - U radu je predstavljen pregled obnovljivih izvora električne energije i njihova mogućnost primene u zaštićenim područjima Srbije. Dat je primer zaštićenog područja Koviljsko-Petrovaradinski rit $i$ manastira Kovilj koji se nalazi u sklopu ovog područja, sa predlogom implementacije solarneenergije na manastirskom imanju $i$ tehno-ekonomskom analizom rešenja.

Ključne reči: Zaštićena područja, obnovljivi izvori energije, fotonaponski sistemi, solarna energija

\begin{abstract}
This paper gives an overview of renewable energy sources and the potential for their implementation in Serbia's nature reserves. It covers the example of Koviljsko-Petrovaradinski rit nature reserve and Kovilj monastery located in the reserve. The paper proposes a solution for the implementation of solarenergy on the monastery estate along with the techno-economic analysis.
\end{abstract}

Keywords: Nature reserves, renewable energy sources photovoltaic systems, solar energy

\section{UVOD}

Zaštićena područja su predeone celine u kojima postoji geološka, biološka ili ekosistemska raznovrsnost i specifičnost, i koje su pod zaštitom države. Kako u zaštićenim područjima postoje mnogo rigorozniji kriterijumi kad je u pitanju zagađivanje životne sredine, od velikog je značaja da se omogući njihovo snabdevanje energijom iz obnovljivih izvora, ali tako da ovi izvori svojom konstrukcijom i radom ne narušavaju samu sredinu. U tom smislu najpogodnije je korišćenje solarne energije, ali isključivo ako se postave na postojeće objekte u obliku krovnih fotonaponskih (FN) elektrana za proizvodnju električne energije i/ili solarnih kolektora za dobijanje toplotne energije (topla voda).

U radu je posmatrano zaštićeno područje KoviljskoPetrovaradinskog rita u blizini Novog Sada i manastir Kovilj koji se nalazi pored ovog zaštićenog područja. Razmatrana je upotreba solarne energije i dat predlog rešenja krovne FN elektrane, uz tehno-ekonomsku analizu rešenja i proračun uštede $\mathrm{u}$ emisiji $\mathrm{CO}_{2}$.

\section{NAPOMENA:}

Ovaj rad proistekao je iz master rada čiji mentor je bio dr Vladimir Katić, red. prof.

\section{ZAŠTIĆENA PODRUČJA SRBIJE}

U Srbiji postoji podela zaštićenih područja $u$ tri kategorije: I kategorija (prirodna dobra od izuzetnog značaja), II kategorija (prirodna dobra od velikog značaja) i III kategorija (značajna prirodna dobra). Kriterijumi po kojima se zaštićena područja svrstavaju u jednu od ove tri kategorije su podeljeni u tri grupe: suštinska svojstva dobra, funkcija i značaj dobra, i ugroženost zaštićenog prirodnog dobra.

Postoji 7 vrsta zaštićenih područja u Srbiji: nacionalni park, park prirode, predeo izuzetnih odlika, opšti i specijalni rezervat prirode, spomenik prirode i zaštićeno stanište.

Po načelu prevencije i predostrožnosti, člana 9 Zakona o zaštiti životne sredine Republike Srbije, svaka aktivnost mora biti planirana i sprovedena na način da: prouzrokuje najmanju moguću promenu u životnoj sredini; predstavlja najmanji rizik po životnu sredinu i zdravlje ljudi; smanji opterećenje prostora i potrošnju sirovina i energije $u$ izgradnji, proizvodnji, distribuciji i upotrebi; uključi mogućnost reciklaže; spreči ili ograniči uticaj na životnu sredinu na samom izvoru zagađivanja [1].

\section{KOVILJSKO-PETROVARADINSKI RIT}

Specijalni rezervat prirode Koviljsko-Petrovaradinski rit se nalazi u jugoistočnoj Bačkoj i prostire na 5895 hektara površine. Ovo je naš najreprezentativniji očuvani ritski kompleks. Unutar Koviljsko-Petrovaradinskog rita postoje područja sva tri stepena režima zaštite, od čega u režim zaštite I stepena spada 373 hektara odnosno 6,33\% površine rezervata, u režim zaštite II stepena spada 1738 hektara odnosno $2,48 \%$ površine rezervata, i u režim zaštite III stepena spada 3784 hektara odnosno 64,19\% površine rezervata.

Koviljsko-Petrovaradinski rit poseduje i nekoliko međunarodnih stepena zaštite, a to su: IBA (značajno područje za ptice od 1989. godine), IPA (značajno područje za biljke od 2005. godine), ICPDR (zaštićeno područje zavisno od vode i značajno za basen Dunava) i pripadnost spisku važnih područja Ramsarske konferencije od 2012. godine. Kako je na postojećim lokalitetima infrastruktura prilično bazična, za potrebe ovog rada uzet je Koviljski manastir, koji predstavlja izazov zbog svoje vrednosti kao kulturnog dobra čija se estetika ne sme narušiti prilikom implementacije novih energetskih izvora [2]. 


\section{SOLARNA ENERGIJA}

Prednost solarne energije je mala količina štetnih gasova koji se proizvode njenom upotrebom (srednja vrednost emitovanog $\mathrm{CO}_{2}$ po kilovat-času iznosi $48 \mathrm{~g}$ za solarne sisteme kapaciteta $10 \mathrm{MW}$ i većeg, odnosno $41 \mathrm{~g} \mathrm{za}$ krovne solarne sisteme manjih kapaciteta). Solarni sistemi su tihi i ne uznemiravaju životinjski svet biosfere, a mogu se postavljati na postojeće objekte, čime se izgled zaštićenog područja minimalno menja. Nedostatak solarne energije je da proizvodnja zavisi od doba dana $i$ vremenskih uslova. Takođe, inicijalna cena izgradnje sistema je visoka, i treba nekoliko godina dok se sistem ne isplati. Prema podacima Ministarstva energetike Srbije, prosek sunčevog zračenja u Srbiji je za oko $40 \%$ veći od evropskog proseka sa $1,4 \mathrm{kWh}$ godišnje po $\mathrm{m}^{2}$. [3].

$\mathrm{Da}$ bi se sunčeva energija uspešno konvertovala $u$ električnu energiju, potrebno je da se koriste fotonaponski elementi. Ovi elementi predstavljaju poluprovodničke strukture koje pretvaraju sunčevu energiju u napon preko fotonaponskog efekta. Fotonaponski sistem je struktura koja povezuje generatore energije (solarne panele) sa potrošačem, uz potrebne elemente za konverziju. U fotonaponski sistem pored fotonaponskih ćelija spadaju i DC/AC konvertori (invertori) i propratna električna oprema koja služi za povezivanje sa električnom mrežom. Na slici 1 je prikazana šema mrežnog FN sistema sa bidirekcionim brojilom.

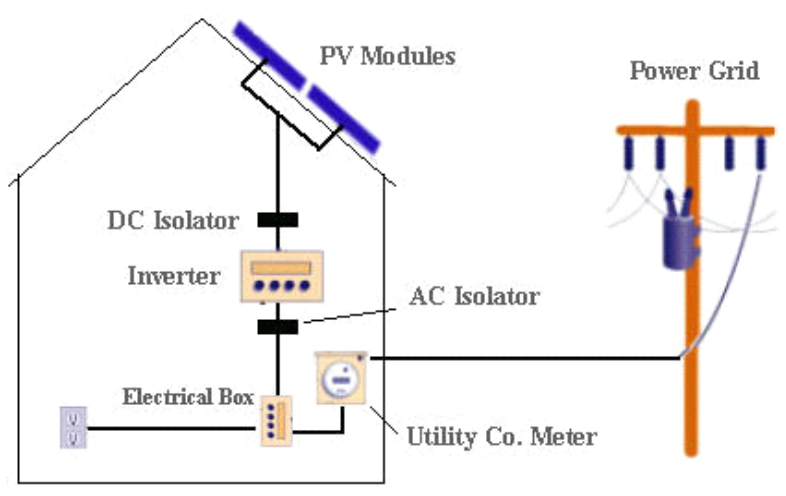

Slika 1. Šema mrežnog fotonaponskog sistema sa bidirekcionim brojilom [4]

\section{PREDLOG ENERGETSKOG REŠENJA ZA MANASTIR KOVILJ}

\subsection{Razmatranje o mogućnostima primene OIE}

Objekti manastira ne spadaju u teritoriju rezervata već se nalaze neposredno pored, pa nema prepreka u smislu ograničenja vezanih za različite stepene zaštite. Međutim, fotonaponski paneli su velikih dimenzija i svojim izgledom bi mogli udroziti manastirski kompleks. Iz tog razloga je lokacija odabrana uz konsultacije sa manastirom.

Predlog rešenja je da se postave fotonaponski paneli na krovu južno-orijentisanog dela manastirskog kompleksa, gde je osunčanost najbolja, a položaj takav da bi paneli ne bi bili vidljivi posetiocima manastira i ne bi estetski narušavali objekat. Na slici 2 prikazana je odabrana lokacija (slika 2.a), kao i dimenzije krovne površine dela koji je odabran za postavljanje FN panela (slika 2.b).

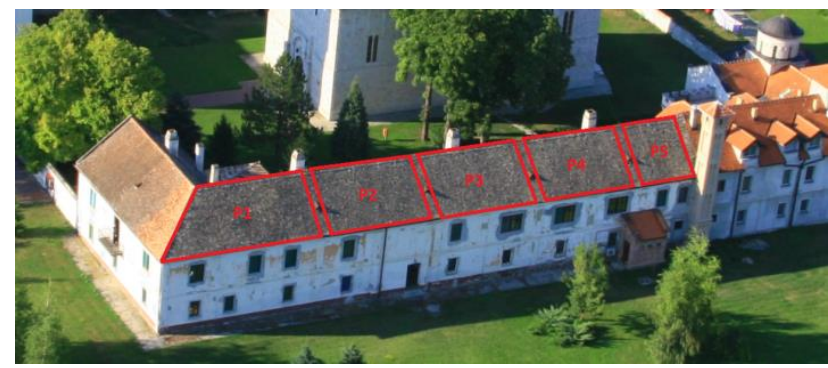

a)

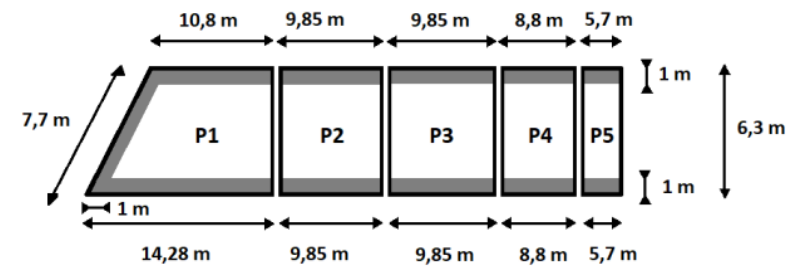

b)

\section{Slika 2. Lokacija FN elektrane i dimenzije krovnih površina}

Izbor solarnog panela je pao na model BenQ SunVivo PM060MW2 dimenzija 1640x992x40 mm, maksimalne snage $300 \mathrm{~W}$, dok je za noseću konstrukciju izabran sistem za krovove sa crepom proizvođača Solar First. Na predviđenu površinu krova moguće je postaviti 102 panela, tako da je ukupna instalisana snaga $30,6 \mathrm{kWp}$.

Kod izbora invertora, uzeto je u obzir da njegova snaga mora biti u rasponu $\pm 10 \%$ projektovane snage sistema, to jest u rasponu od $27,5 \mathrm{~kW}$ do $33,6 \mathrm{~kW}$. Za idejno rešenje je izabran trofazni invertor TRIO-27.6-TL-OUTD-S2F400 proizvođača ABB snage $27,6 \mathrm{~kW}$.

$\mathrm{Za}$ nadzemni kabl je izabran model Solar $125 \mathrm{~S}$ flex UL/EN proizvođača BETAflam, dok je za podzemni kabl izabran model PP 004 x6 proizvođača Novkabel.

Solarna FN elektrana predviđena je da bude direktno priključena na mrežu (In-grid), odnosno da se sva proizvedena energija isporučuje EES-u. Manastir bi mogao da prihoduje, ako bi se za isporučenu energiju koristila povlašćena (feed-in) tarifa ili na bazi kompenzacije.

\subsection{PVGIS proračun}

$\mathrm{Za}$ proračun je korišćen softver Photovoltaic Geographical Information System (PVGIS) koji uzima u obzir intenzitet sunčevog zračenja po mesecima $u$ zavisnosti od geografskih koordinata, i omogućava procenu proizvodnje sistema $\mathrm{u}$ toku jedne godine. Unošenjem geografskih koordinata manastira i ostalih podataka (snaga, položaj, nagnutost i sl.), dobija se da je godišnja proizvodnja energije PV sistema $39.800 \mathrm{kWh}$, dok je vrednost godišnjeg sunčevog zračenja 1580 $\mathrm{kWh} / \mathrm{m}^{2}$. Procenjeni gubici sistema na osnovu softverske simulacije: gubici zbog upadnog ugla svetlosti: $-2,8 \%$, spektralno rasejanje: $1,1 \%$, gubici zbog temperature i niskog zračenja: 6,8\%, ukupni gubici: $-17,6 \%$. U tabeli 1 su prikazane vrednosti prosečna mesečna proizvodnja električne energije sistema $(\mathrm{Em}) \mathrm{u} \mathrm{kWh} / \mathrm{m}^{2}$, prosečnog 
sunčevog zračenja na FN modul $(\mathrm{Hm}) \mathrm{u} \mathrm{kWh} / \mathrm{m}^{2}$ i standardne devijacije (SDm) u kWh.

Tabela 1. Mesečna proizvodnja električne energije, sunčevo zračenje $i$ standardna devijacija

\begin{tabular}{|c|c|c|c|}
\hline Mesec & Em & Hm & SDm \\
\hline Januar & 1460 & 53,7 & 282 \\
\hline Februar & 2000 & 73,4 & 306 \\
\hline Mart & 3540 & 134 & 487 \\
\hline April & 4160 & 164 & 504 \\
\hline Maj & 4390 & 177 & 297 \\
\hline Jun & 4440 & 183 & 332 \\
\hline Jul & 4880 & 204 & 293 \\
\hline Avgust & 4810 & 200 & 250 \\
\hline Septembar & 3710 & 149 & 500 \\
\hline Oktobar & 3030 & 117 & 383 \\
\hline Novembar & 2110 & 78,3 & 219 \\
\hline Decembar & 1240 & 45,6 & 294 \\
\hline
\end{tabular}

Proizvodnja električne energije dostiže svoj maksimum od $4.880 \mathrm{kWh} \mathrm{u}$ toku meseca jula, dok je očekivani minimum proizvodnje u toku decembra, i iznosi 1.240 $\mathrm{kWh}$, što je prikazano na slici 3.

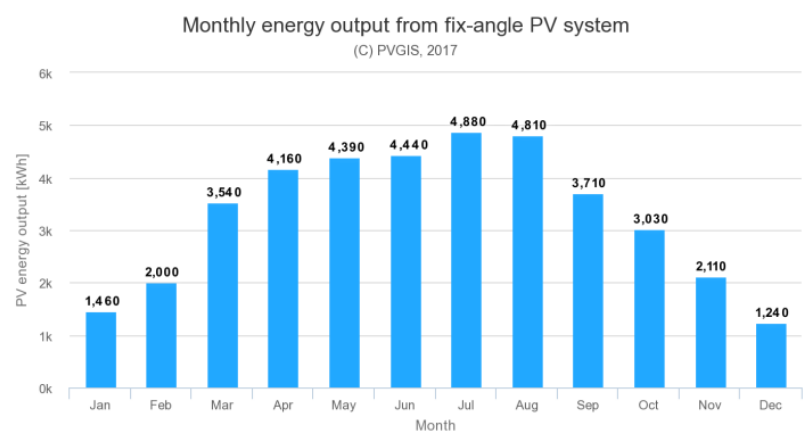

Slika 3. Mesečna proizvodnja el. energije PV sistema

Nivo sunčevog zračenja dostiže maksimum od 204 $\mathrm{kWh} / \mathrm{m}^{2} \mathrm{u}$ julu, dok je najniži tokom decembra i iznosi $45,5 \mathrm{kWh} / \mathrm{m}^{2}$, što je prikazano na slici 4.

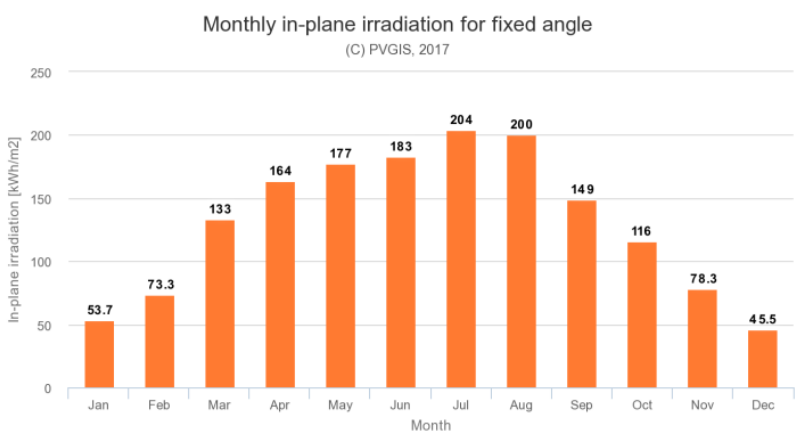

Slika 4. Mesečno sunčevo zračenje na PV sistem

\subsection{Tehno-ekonomska analiza}

Uzevši u obzir okvirne troškove opreme i održavanja projektovane solarne elektrane, potrebno je uložiti $24.561 €$. U tabeli 2 su prikazane cene i količina potrebne opreme kao i ostali troškovi, koji odlaze na godišnje održavanje sistema.
Tabela 2. Lista opreme potrebne za izgradnju elektrane

\begin{tabular}{|c|c|c|c|}
\hline vrsta opreme & cena po jedinici $(€)$ & količina & ukupno $(€)$ \\
\hline solami panel & 182 & 102 & 18564 \\
\hline invertor & 3499 & 1 & 3499 \\
\hline noseća konstrukcija & 1500 & 1 & 1500 \\
\hline nadzemni kabl & 1,09 & 450 & 490.5 \\
\hline podzemni kabl & 3,15 & 50 & 157.5 \\
\hline razvodni orman & 200 & 1 & 200 \\
\hline ostali troškovi & $/$ & $/$ & 150 \\
\hline UKUPNO & \multicolumn{3}{|l}{} \\
\hline
\end{tabular}

Kako konkretna godišnja potrošnja električne energije u manastiru nije poznata, napravljena je procena na osnovu broja i vrste potrošača. Dobijeno je da manastir godišnje potroši $35.479,2 \mathrm{kWh}$, što znači da se uz proračunatu proizvodnju električne energije u solarnoj elektrani godišnje proizvede višak od 4.290,8 kWh. Na slici 5 je prikazan odnos proizvedene i utrošene električne energije po mesecima.

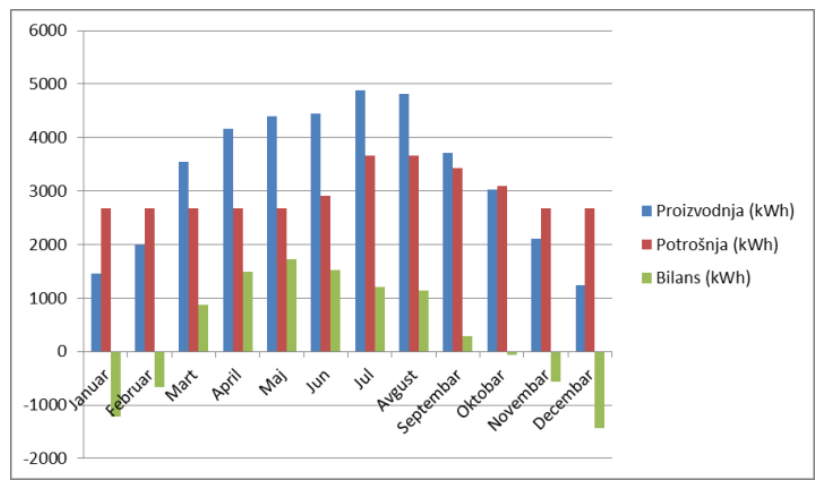

Slika 5. Grafički prikaz bilansa mesečne proizvodnje $i$ potrošnje električne energije

Nakon analize dva slučaja: prodaje viška proizvedene električne energije elektrodistribuciji po podsticajnoj ceni, i prodaja celokupne proizvedene električne energije elektrodistribuciji po podsticajnoj ceni, utvrđeno je da je prva opcija isplativija. Prilikom proračuna isplativosti je uzeto u obzir da solarni paneli godišnje gube $0,5 \%$ snage, te da će srazmerno tome godišnja proizvodnja električne energije biti manja iz godine u godinu. Takođe su uzeti u obzir godišnji troškovi održavanja elektrane koji iznose 150 evra godišnje, i ušteda na računima za električnu energiju koji su procenjeni na 4487,1 € godišnje zbog velikih potrošača u vidu opreme za proizvodnju sveća, sira, meda i voćnih prerađevina. U tabeli 3 je prikazana isplativost elektrane u slučaju prodaje viška električne energije. Na slici 6 je prikazano da se sistem isplati nakon 6 godina rada, uz podsticajnu cenu od $0,121 \mathrm{c} € / \mathrm{kWh}$.

Tabela 3. Isplativost solarne elektrane uz prodaju viška proizvedene električne energije

\begin{tabular}{|c|c|c|c|c|c|}
\hline Godina & $\begin{array}{c}\text { Godišnja } \\
\text { zarada na } \\
\text { proizvedenoj } \\
\text { el. energiji }(€)\end{array}$ & $\begin{array}{c}\text { Godišnji } \\
\text { troškovi } \\
\text { održavanja ( } €\end{array}$ & $\begin{array}{c}\text { Godišnja } \\
\text { ušteda na } \\
\text { računima }(€)\end{array}$ & $\begin{array}{c}\text { Ukupna } \\
\text { godišnja } \\
\text { zarada }(€)\end{array}$ & $\begin{array}{c}\text { Isplativost } \\
(€)\end{array}$ \\
\hline 1. godina & 523,3 & 150 & 4487,1 & 4860,4 & $-19700,6$ \\
\hline 2. godina & 499 & 150 & 4487,1 & 4836,1 & $-14864,4$ \\
\hline 3. godina & 474,8 & 150 & 4487,1 & 4811,9 & $-10052,5$ \\
\hline 4. godina & 450,5 & 150 & 4487,1 & 4787,6 & $-5264,9$ \\
\hline 5. godina & 426,3 & 150 & 4487,1 & 4763,4 & $-501,5$ \\
\hline 6. godina & 402 & 150 & 4487,1 & 4739,1 & 4237,6 \\
\hline
\end{tabular}




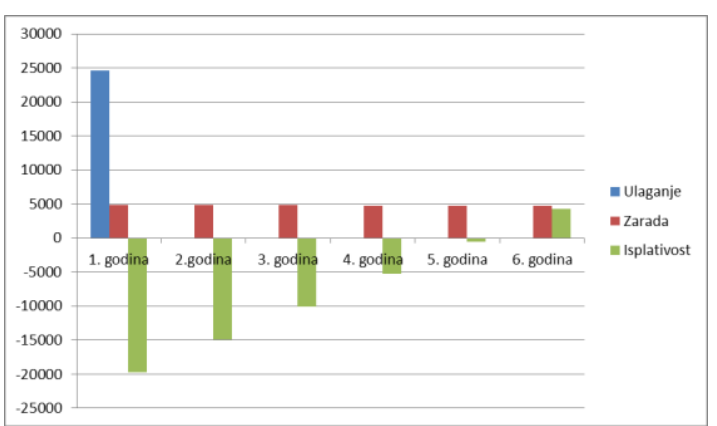

Slika 6. Grafički prikaz isplativosti elektrane pri prodaji viška el. energije po podsticajnoj ceni

U drugom posmatranom slučaju, solarna elektrana se u potpunosti koristi za prodaju električne energije, te je zarada na prodaji mnogo veća, ali nema uštede na računima koji iznose jednako kao i pre implementacije solarne elektrane. $\mathrm{Na}$ slici 7 je prikazana isplativost elektrane pri prodaji celokupne proizvedene energije.

Tabela 4. Isplativost solarne elektrane uz prodaju celokupne proizvedene električne energije

\begin{tabular}{|l|c|c|c|c|c|}
\hline Godina & $\begin{array}{c}\text { Godišnja } \\
\text { zarada na } \\
\text { proizvedenoj } \\
\text { el. energiji }(€)\end{array}$ & $\begin{array}{c}\text { Godišnji } \\
\text { troškovi } \\
\text { održavanja } \\
(€)\end{array}$ & $\begin{array}{c}\text { Godišnja } \\
\text { ušteda na } \\
\text { računima }(€)\end{array}$ & $\begin{array}{c}\text { Ukupna } \\
\text { godišnja } \\
\text { zarada }(€)\end{array}$ & $\begin{array}{c}\text { Isplativost } \\
(€)\end{array}$ \\
\hline 1. godina & 4850,3 & 150 & 0 & 4700,3 & $-19860,6$ \\
\hline 2. godina & 4826,1 & 150 & 0 & 4676,1 & $-15184,5$ \\
\hline 3. godina & 4801,8 & 150 & 0 & 4651,8 & $-10532,7$ \\
\hline 4. godina & 4777,6 & 150 & 0 & 4627,6 & $-5905,1$ \\
\hline 5. godina & 4753,3 & 150 & 0 & 4603,3 & $-1301,8$ \\
\hline 6. godina & 4729,1 & 150 & 0 & 4579,1 & 3277,3 \\
\hline
\end{tabular}

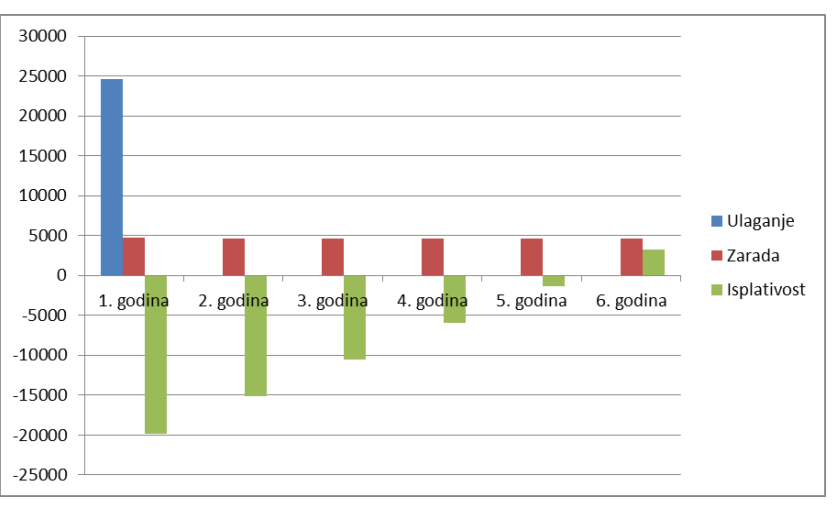

Slika 7. Prikaz isplativosti elektrane pri prodaji celokupne proizvedene el. energije

Iako bi, zbog podsticajne cene, bilo logično pretpostaviti da je ova varijanta isplativija, to nije slučaj zbog visokih mesečnih računa za električnu energiju. Kako manastir prelazi granicu od $1600 \mathrm{kWh}$ mesečne potrošnje, ulazi u crvenu tarifnu zonu gde je cena $0,13 \mathrm{c} € / \mathrm{kWh}$, što je za 0,01 c€ više od podsticajne cene. Rešenje bi bio prelazak na višetarifno merenje, čime bi, korišćenjem pogodnosti niže tarife, računi bili znatno manji, pa bi opcija prodaje celokupne proizvedene električne energije bila isplativija.

\subsection{Ušteda $\mathrm{CO}_{2}$}

$\mathrm{Na}$ osnovu Izveštaja o stanju životne sredine u JP "Elektroprivreda Srbije" za 2018. godinu[5], u TE "Nikola Tesla" je u toku 2018. godine proizvedeno ukupno 16.614,7 GWh električne energije, a emitovano je
19.341.895 tona $\mathrm{CO}_{2}$, što znači da ova TE godišnje emituje $1,164 \mathrm{~kg} / \mathrm{kWh} \mathrm{CO}_{2}$. Kako projektovani solarni sistem godišnje proizvodi $39.800 \mathrm{kWh}$, uštedelo bi se ukupno $46327.2 \mathrm{~kg} \mathrm{CO}$ na godišnjem nivou prelaskom na solarni sistem napajanja.

\section{ZAKLJUČAK}

Primena obnovljivih izvora energije u zaštićenim sredinama predstavlja izazov zbog raznih ograničavajućih faktora koji se moraju uzeti u obzir prilikom analize. U radu je razmatrana mogućnost instalacije solarne elektrane na način da estetski ne narušava izgled manastira Kovilj, i utvrđeno da je moguće napraviti elektranu snage $39.800 \mathrm{kWh}$ koja bi dala pozitivan godišnji bilans od 4290,8 kWh.

Zbog male osunčanosti u zimskim mesecima, proizvodnja elektrane nije dovoljna da pokrije potrošnju, te je neophodno osloniti se na struju iz elektrodistribucije. Razmatrana su dva slučaja: prodaja celokupne proizvedene električne energije, i prodaja samo viška proizvedene energije. U oba slučaja, elektrana se samoisplaćuje nakon šest godina upotrebe, uz podsticajne cene fid-in tarife. Iako je u ovom radu posmatrana samo upotreba solarne energije, postoji prostor za dalje analiziranje primene obnovljivih izvora energije kroz upotrebu geotermalnih pumpi.

\section{LITERATURA}

[1] Zakon o zaštiti životne sredine, Sl. glasnik RS, br. 135/2004, 36/2009

[2] Specijalni rezervat prirode "Koviljsko-Petrovaradinski rit", predlog za stavljanje pod zaštitu kao zaštićenog područja I kategorije, studija zaštite, Pokrajinski zavod za zaštitu prirode, 2010.

[3] "Fotonaponski sistemi", Studija NPEE, evidencioni broj EE704-1052A, Beograd 2004.

[4] "Grid-Connected Power Systems", Murdoch University, 2008.

[5] Izveštaj o stanju životne sredine u JP „Elektroprivreda Srbije“ za 2018. godinu.

\section{Kratka biografija:}

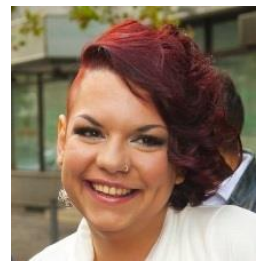

Dragana Stajić rođena je u Novom Sadu 1984. god. Diplomske-master studije na studijskom programu Energetika, elektronika i telekomunikacije upisala je školske 2003/2004. Na studijama se opredelila za modul Mikroračunarska elektronika. Master rad je odbranila 2019. godine.

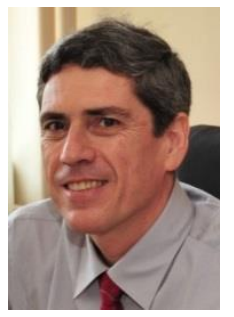

Vladimir A. Katić, red.prof. rođen je 1954. godine u Novom Sadu. Doktorirao je na Univerzitetu u Beogradu 1991. godine. Za redovnog profesora Univerziteta u Novom Sadu izabran je 2002. god. Oblasti interesovanja su mu energetska elektronika, obnovljivi izvori električne energije, kvalitet električne energije i električna vozila. 